\title{
Teoría de la prosa, de \\ \& Ricardo Piglia
}

Ricardo Piglia (1941-2017) fue uno de los escritores argentinos más destacados de su generación. Novelas como Respiración artificial (1980), Plata quemada (1997), Blanco nocturno (2010) o El camino de Ida (2013), le aseguran un lugar prominente en la literatura de América Latina y de su país. Piglia fue también un destacado crítico y se dedicó profesionalmente a la enseñanza de la literatura. Se desempeñó como catedrático en la Universidad de Buenos Aires, la Universidad de Princeton y la Universidad de California en Davis. No sólo fue un continuador de la tradición de plantear la crítica como una forma literaria como lo demuestra en colecciones de ensayos como Crítica y ficción (1996), Formas breves (2000) o El último lector (2005); Piglia propuso lo que llamó "crítica de escritor", un modo de lectura del texto literario que no va tanto a su significado como a desentrañar el dispositivo, a desarmar los mecanismos de funcionamiento del texto narrativo, desde la mirada del oficio de narrador. Esa mirada fue la que puso a operar a lo largo de muchos de los seminarios que impartió, en los que entusiasmaba a sus estudiantes por la agudeza y minuciosidad de sus lecturas, pero que también se convertían en un espacio de reflexión sobre la escritura misma. En sus últimos años, trabajó en transformar algunos de estos cursos en libros, como es el caso de Las tres vanguardias: Saer, Puig, Walsh, que recoge once clases de un seminario que impartió en la Universidad de Buenos Aires y que apareció en 2016.

Teoría de la prosa, que aparece póstumamente, lo reescribió su autor a partir de las grabaciones de un seminario dictado en la Universidad de Princeton en 1995, que dedicó enteramente a las novelas cortas de Juan Carlos Onetti. En estas páginas, parte de la idea de que la novela corta o nouvelle no es una simple convención editorial externa, basada en el número de páginas de un texto narrativo, sino una forma literaria en sentido pleno. Apoyado en la heterogénea constelación de 
Gilles Deleuze, Erich Auerbach, Viktor Shklovsky y, por supuesto, Walter Benjamin, muestra que la novela corta o nouvelle se organiza en torno al principio estructurador del secreto. El secreto no es lo mismo que el enigma, propio del relato policial. No se trata así de revelar a través de la narración los datos desconocidos de un suceso, sino de algo distinto, que opera precisamente en el sentido inverso. El secreto es algo que no se quiere 0 no se puede develar. De esta forma, la nouvelle presenta varias versiones en torno a un suceso del que no tenemos todos los elementos. El secreto, según muestra Erich Auerbach, no es propiamente un tema, sino un dispositivo que opera al nivel del marco narrativo, de la situación externa desde la que se aborda tentativamente la historia.

Este mecanismo lo explora Piglia con mucha atención en las nouvelles de Onetti, autor que, a su entender, maneja el género con una singular maestría y le permite entregarnos una nueva visión de la realidad a través de la innovación formal, de llevar el dispositivo del secreto a un nuevo nivel. Así se explican esas atmósferas de indeterminación y ambigüedad que parecen ser propias del novelista uruguayo. Así es posible entender la originalidad de Onetti dentro del llamado Boom latinoamericano. Se ha insistido en que Onetti construye su propia geografía literaria con Santa María, a la manera del Yoknapatawpha de Faulkner o del Macondo de García Márquez. Pero Onetti vuelve más borrosa la frontera entre lo real y lo inventado que estos autores, pues no lo anima un afán de reencantamiento a través de la ficción. Es decir, a diferencia de la fórmula "la verdad de las mentiras" acuñada por Vargas Llosa, no busca exaltar el acto demiúrgico en que la ominipotencia del creador literario supera la prosa del mundo cotidiano. Muy por el contrario, la imaginación en Onetti pone al desnudo los mecanismos violentos de dominación de manera todavía más nítida.

Esta intuición es original, pues lejos de asimilar a Onetti con la corriente de lo real-maravilloso o de la ominipotencia demiúrgica, lo Lleva a la tradición del relato fantástico distópico, que Piglia, en otros trabajos, ha señalado como la tradición narrativa distintiva del Cono Sur. Pigilia traza una genealogía literaria que emparenta a Onetti con Faulkner, sino con Jorge Luis Borges, Roberto Arlt y Henry James. La nouvelle onettiana sería pues la síntesis más decantada de dichos hilos literarios.

En la obra crítica de Piglia, el lector se encuentra no sólo con erudición sino con lúcidas intuiciones. Ahora bien, a menudo queda el regusto de que no le saca suficiente partido a las ideas que propone ni las originales constelaciones críticas 
o literarias que traza. Pareciera que el método de la "lectura de escritor" que, por una parte, tiene el acierto de desmontar con minucia los mecanismos narrativos de las obras; por otra, lo exime de extraer las consecuencias de su propia lectura. Así regresa la autoridad un tanto arbitraria del demiurgo que no necesita dar razones de su comprensión superior. Es así como Piglia nos ofrece lecturas muy inteligentes de la arquitectura narrativa de Onetti, pero se pueda corto en dar cuenta del por qué de las formas, del tipo de verdad del mundo que nos aportan. ¿Qué relación hay entre esta perspectiva del mundo cotidiano dominado por la ceguera de los prejuicios y un mundo de la imaginación pervertido por los deseos de dominación? ¿Por qué Onetti nos presenta en sus novelas cortas el estupor de esta aparente sin salida? Es una tarea que deja pendiente.

No puedo omitir mencionar que otro acierto del libro es que invita hacer una lectura en paralelo de las nouvelles de Onetti que se aborda: El pozo, La cara de la desgracia, Los adioses, Para una tumba sin nombre, Tan triste como ella y Para una tumba sin nombre. Propone leer cada nouvelle antes del capítulo en el cual se comenta. De esta manera, noz permite redescubrir esta parte de la obra de Onetti que la crítica suele poner en un lugar menor con respecto a las celebradas novelas largas, como La vida breve, El astillero o Juntacádaveres, en las cuales se enfatiza mejor el acto demiúrgico de Santa María. He de decir, desde mi modesta opinión, que entre las nouvelles son precisamente aquellas en las cuales el gesto demiúrgico es menos enfático, las que menos han envejecido, es decir han sobrevivido mucho mejor el discurso del Boom, que en su momento llegó a fagocitar a un autor que le era más bien ajeno, como Onetti. Me impactaron de manera muy especial la relectura de Los adioses y Tan triste como ella. Los adioses recrea, desde el marco narrativo de los espectadores de vidas ajenas, la miseria de una vida empobrecida que se alimenta de las proyecciones de sus fantasías en aquellos a los que ve con desprecio y suspicacia. Esta sería una novela que se enriquecería de un diálogo más detenido con "El narrador" de Walter Benjamin, su ensayo sobre la narración y la destrucción de la experiencia en el mundo moderno. Tan triste como ella, por otra parte, es la magistral y desgarradora radiografía de la miseria de la vida conyugal de la clase media provinciana.

En Teoría del lector encontramos no tanto al Piglia crítico capaz de hacer ejercicios de prosa literaria brillante a partir de sus lecturas, sino a la figura mucho más modesta del maestro que nos hace cómplices de recorridos apasionados y lúcidos de descubrimiento. Con ello, nos 
entrega ideas que son invaluables tiano y como de la realidad latinoaen la búsqueda de ampliar nuestra mericana y humana.

comprensión tanto del mundo onet-

\section{Referencias bibliográficas}

- Piglia, Ricardo (2019). Teoría de la prosa. Buenos Aires: Eterna Cadencia. 